\title{
Pooled analysis of clinical trial data evaluating the safety and effectiveness of diclofenac epolamine topical patch $1.3 \%$ for the treatment of acute ankle sprain
}

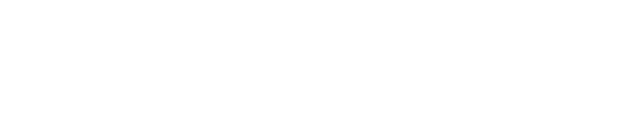

\author{
David R Lionberger ${ }^{1}$ \\ Eric Joussellin ${ }^{2}$ \\ Jillmarie Yanchick ${ }^{3}$ \\ Merrell Magelli,4 \\ Arturo Lanzarotti ${ }^{5}$ \\ 'Southwest Orthopedic Group, \\ LLP, Houston, TX, USA; ${ }^{2}$ Institut \\ National du Sport, Paris, France; \\ ${ }^{3}$ Formerly Alpharma Pharmaceuticals \\ LLC, Piscataway, NJ, USA; ${ }^{4} \mathrm{GTx}$, \\ Inc., Memphis, TN, USA; ${ }^{5}$ nstitut \\ Biochimique SA, Switzerland
}

\begin{abstract}
This pooled analysis assessed the efficacy and safety of the diclofenac epolamine topical patch $1.3 \%$ (DETP) for the treatment of acute mild-to-moderate ankle sprain. Data from 2 randomized, double-blind, placebo-controlled studies enrolling 274 male and female patients aged 18 to 65 years with acute ankle sprain were pooled and evaluated. The primary end point was pain reduction on movement assessed using a $100 \mathrm{~mm}$ visual analog scale (VAS). Safety and tolerability were also assessed. Beginning approximately 3 hours after initial treatment, DETP-treated patients experienced statistically significant and sustained lower mean VAS scores in pain intensity on movement (mean $\pm \mathrm{SD}, 54.1 \pm 20.0 \mathrm{~mm}$ versus $60.3 \pm 16.8 \mathrm{~mm}$ ) compared with placebo-treated patients, representing a $20 \%$ versus $13 \%$ reduction in VAS pain scores from baseline $(P=0.012)$. This statistically significant difference in mean VAS score was maintained through day 7 (9.4 $\pm 14.4 \mathrm{~mm}$ versus $18.4 \pm 18.2 \mathrm{~mm}, P<0.0001)$. The DETP and placebo patches were well tolerated. These results further confirm the efficacy and safety of DETP for the treatment of acute pain from ankle sprains.
\end{abstract}

Keywords: soft tissue injury, acute pain, visual analog scale, clinical trial, double-blind, safety

\section{Introduction}

Ankle sprains are among the most prevalent injuries in the field of sports medicine. In a recent review by Fong et al, systematic analyses of 227 epidemiological studies from 38 countries showed that ankle sprains were the most common ankle injury in 33 of 43 sports examined. ${ }^{1}$ In addition, in a review of a database reporting more than 139 million injuries from 1997 to $2001,{ }^{2}$ it was found that $20 \%$ of all sports-related injuries were sprains and strains, accounting for an estimated US\$2 billion in treatment and rehabilitation costs in the United States (US) alone. ${ }^{3}$ These numbers likely underestimate the prevalence of acute ankle sprains since many individuals do not contact their physicians following this kind of injury. Due to the widespread occurrence and substantial health care costs associated with ankle sprains, clinicians are continuously focusing on more efficient and cost-effective methods for treatment of acute ankle injuries.

Guidelines for treatment of uncomplicated ankle sprains call for the use of rest, ice, compression, and elevation (RICE). ${ }^{4}$ Additionally, orally administered non-steroidal anti-inflammatory drugs (NSAIDs) have been demonstrated to be effective for the treatment of pain due to ankle sprains. ${ }^{5,6}$ Unfortunately, the use of NSAIDs is limited
Correspondence: David R Lionberger 6560 Fannin Street, Houston,

Texas 77030, USA

Tel +I7I3 3334100

Fax + I7I3 333 4I0

Email dlionberger@mysurgeon.com 
in some patients due to gastrointestinal (GI) toxicity, and cardiovascular adverse events (AEs). ${ }^{7,8}$ NSAIDs carry a risk of serious AEs of the GI tract. ${ }^{9,10}$ In fact, at the time of a review by Wolfe and colleagues in $1999,{ }^{10}$ GI bleeding secondary to NSAID use was the fifteenth leading cause of death in the US. Cardiovascular AEs have also been associated with both short- and long-term use of NSAIDs. ${ }^{11,12}$

Many patients with ankle sprains may also be taking low dose aspirin (LDA) or other antiplatet therapies for cardioprophylaxis, placing them at increased risk for GI events when NSAIDs are used. ${ }^{13}$ In addition, some commonly used NSAIDs, such as naproxen and ibuprofen, but not diclofenac, can have pronounced effects on the antiplatelet properties of LDA. ${ }^{14-18}$

Recently released topical NSAID formulations were specifically designed to deliver NSAIDs, in a targeted manner, to the affected location while simultaneously reducing the systemic exposure of the active agent. One such formulation is the diclofenac epolamine topical patch $1.3 \%$ (DETP). The DETP is capable of targeted delivery to sites of injury with superior efficacy to NSAID-containing gels and ointments while providing significantly lower systemic exposure to diclofenac than low-dose oral administration. ${ }^{19-26}$ Compared with diclofenac $50 \mathrm{mg}$ oral, which is one-third the daily dose studied in acute ankle injury, the relative systemic bioavailability of diclofenac from the DETP is $0.7 \% \pm 0.4 \% .{ }^{19}$

In a number of randomized controlled studies, DETP treatment displayed superiority versus placebo in time to pain resolution in patients treated for minor sports injuries. ${ }^{20-22,25}$ Several clinical studies have also shown DETP to be efficacious in the treatment of pain due to osteoarthritis, ${ }^{23,27}$ and tendonitis. ${ }^{24,26}$ In 2 separate randomized, double-blind, placebo-controlled studies, patients with acute pain due to mild-to-moderate ankle sprain treated with DETP experienced statistically significantly reduced pain on movement compared with placebo patch. ${ }^{20,22}$ Although these studies were conducted independently, there was remarkable similarity in the design and methods of the trials. As a result, we felt that a pooling of the data could allow analysis of treatment effects across a larger, ie, pooled, population of patients and potentially validate the conclusions that each trial determined independently. Further, there are limited data published on the use of DETP and we felt that practitioners in the US might not be familiar with the results of the 2 French studies. Therefore, data from these 2 studies were pooled to explore overall efficacy and safety for the treatment of acute pain due to mild-to-moderate ankle sprain.

\section{Patients and methods}

\section{Study design}

Two studies of nearly identical design conducted in France from April 1996 to May 1999 by 45 trained investigators under the supervision of a study coordinator were pooled for this analysis. Study 1 refers to the DETP trial by Joussellin ${ }^{20}$ and Study 2 refers to the DETP trial by Saillant. ${ }^{22}$ Both studies were placebo-controlled, randomized, double-blind, multicenter, parallel group, outpatient studies with the same primary efficacy variable. As such, the data obtained from these studies were ideal for a pooled analysis of efficacy data (in particular, the primary end point). The studies were conducted in conformity with the Declaration of Helsinki and the French Ethical Committee Guidelines for the protection of persons participating in biomedical research. The objective of both studies was to evaluate the efficacy and safety of the DETP compared with placebo in the treatment of mild-tomoderate ankle sprain when the patch was administered once daily for up to 7 days. The primary efficacy variable was pain on movement and was assessed by the patient on a $100 \mathrm{~mm}$ visual analog scale (VAS). Secondary efficacy variables included analgesic effects, perimalleolar edema, global efficacy measured by both the patient and the investigator, number of paracetamol (acetaminophen) tablets used as rescue medication, overall tolerability, and reporting of AEs. These variables are discussed in further detail below.

\section{Patients}

In total, 274 male and female patients, aged 18 to 65 years, were enrolled in the 2 studies; 134 patients participated in Study 1 and 140 participated in Study 2. The inclusion criteria included: 1) The patient had to have an acute ankle sprain, with the injury dating back less than 48 hours; 2) Evaluation of spontaneous pain on a $100 \mathrm{~mm}$ VAS had to be $\geq 50 \mathrm{~mm}$; 3) The sprain could not require orthopedic or surgical treatment; 4) The patient could not have received treatment prior to study entry; and 5) The injury had to justify NSAID therapy for up to 7 days. The exclusion criteria included: 1) The patient was pregnant or lactating; 2) The patient had allergies to NSAIDs or aspirin; 3) The patient had open skin lesions at the site of injury; 4) The patient had a history of recurrent sprains; 5) The patient had used any kind of topical products, enzyme therapy by local or oral route, or corticosteroids, or NSAIDs (including aspirin) by oral or parenteral route less than 7 days prior to study entry; 6) The patient had taken any analgesic less than 6 hours prior to inclusion; 7) The patient had used physiotherapy or 
any type of alternate medicine; or 8) The patient needed to be treated with anticoagulants during the study period. All patients were informed of the details of the entire study (for both studies) including: purpose, procedures, data collection methods, test articles, risks, potential AEs, rescue measures, and confidentiality. Patients were only allowed to enter the study after the informed consent had been signed.

\section{Procedures}

Patients were recruited according to the inclusion/exclusion criteria listed above and randomized to 1 of 2 treatment groups (DETP or placebo patch). Following randomization, patients underwent a general exam as well as a study-specific examination of the injured joint including swelling, skin condition, functional impairment, pain at rest, pain on passive stretch, pain on pressure, and pain on single foot leaning. The patients were asked to score their pain levels using a VAS (from 0 to $100 \mathrm{~mm}$ ) before the first patch was applied to the injured ankle. They were then instructed on treatment regimen such that a new patch was applied every 24 hours, as well as on how to perform the daily pain evaluation in their personal diaries. The patients came back to the clinic for a follow-up visit on days 3 and 7; at these visits all primary and secondary efficacy parameters, as well as tolerability and safety assessments, were evaluated in the presence of the primary investigator. The visit on day 7 concluded the patient's participation in the study. Concomitant medications/therapies allowed were ice application and paracetamol use (not within 3 hours of the first application of the product and not to exceed $3 \mathrm{~g}$ per day). Use of these supplemental measures was detailed on the case report form for each patient. Additionally, the amount of rescue medication consumed was calculated at the end of the study.

\section{Outcome measures}

Outcome measures used included VAS, analgesic efficacy, circumferential swelling, global efficacy, overall tolerability, and AE monitoring.

Pain on movement was the primary efficacy variable and was defined as pain perceived by the patient during normal daily activities. The pain level was self-assessed by each patient on a $100 \mathrm{~mm}$ Huskisson VAS where 0 was equivalent to no pain and 100 corresponded to severe pain. Pain assessments were completed in the presence of the investigator at baseline and on days 3 and 7. Self-assessments were completed in a diary format for hours 1 through 6 after the first application of the patch, as well as at $8 \mathrm{pm}$ that evening, and $8 \mathrm{am}, 12 \mathrm{pm}$, and $8 \mathrm{pm}$ on days 1 and 2 after the initial application, and at 8 am on day 3 . At the end of the 7-day period, treatment was considered a success only for those patients who registered at least a $30 \%$ decrease from baseline in VAS pain.

\section{Statistical analyses}

Pooled efficacy analyses were conducted using adjusted baseline values in order to account for any potential impact on the results. The level of significance for all tests was $P=0.05$. For the primary efficacy variable, pain on movement, pooled data were analyzed and summarized (mean, median, standard deviation) for all patients included in the 2 trials that underwent at least 1 patch application (274 patients in total). The initial characteristics of the patients at the time of inclusion in the study were compared between treatment groups using an analysis of variance (ANOVA) or the Chi-square test, for quantitative and qualitative variables, respectively.

In order to provide additional clinical relevance, actual scores and percent reduction in post-treatment score from baseline were compared between groups at each time point using the Wilcoxon rank-sum nonparametric test. Missing values for the primary efficacy analysis were substituted using the last observation carried forward technique for all patients who did not complete the evaluation per the original protocol procedures or who interrupted their participation in the study for any reason.

For all secondary efficacy variables, data from both individual studies were collected and analyzed in a comparable manner; these data were not pooled. For categorical assessments, such as those used for analgesic effects, global efficacy, and tolerability, Fisher exact test was used to compare the scores of DETP-treated patients with placebotreated patients. For comparisons to assess swelling in the injured ankle versus the healthy ankle the Mann-Whitney non-parametric test was used, and to determine potential differences in rescue medication consumed, a Student's $t$-test was employed.

\section{Results}

\section{Patient population}

A total of 274 male and female patients, aged 18 to 65 years, were enrolled in the 2 studies (134 in Study 1 and 140 in Study 2; Figure 1). Of the patients enrolled, a total of 136 were randomized to placebo and 138 were randomized to the DETP group (Figure 1). In total, 257 (94\%) patients completed the 2 studies. Table 1 displays the mean values 


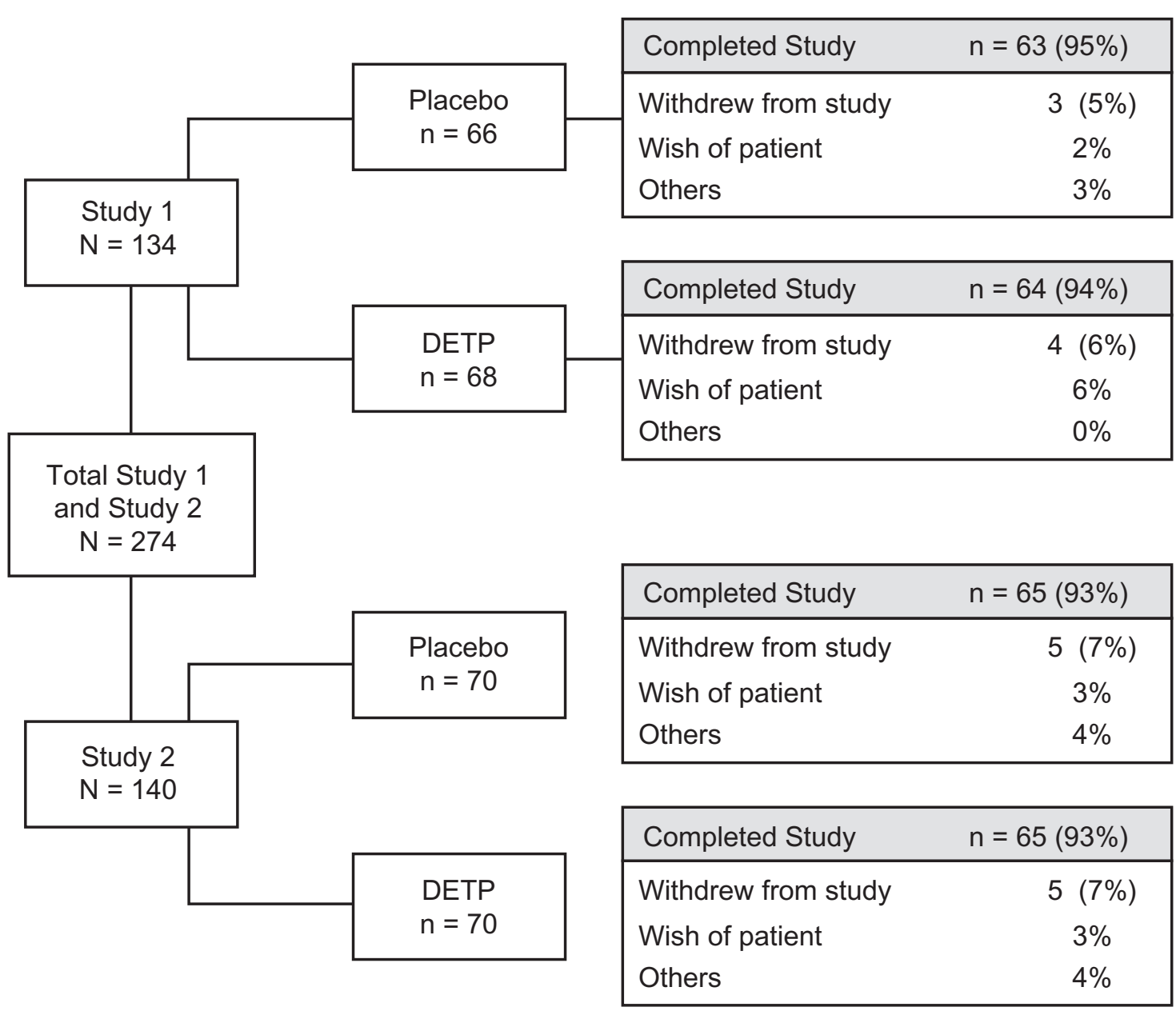

Figure I Patient disposition flow chart showing the total number of patients randomized to each study (by treatment group), as well as the number of individuals that completed each study (by treatment group).

Abbreviation: DEPT, diclofenac epolamine topical patch.

for the demographic and baseline injury characteristics of each treatment group. There were no statistically significant differences between treatment groups for any characteristic at baseline (Table 1). The majority $(n=203)$ of patients were experiencing moderate-to-severe functional impairment at baseline. The mean \pm standard deviation (range) baseline pain scores were $67.0 \pm 10.6 \mathrm{~mm}(50 \mathrm{~mm}-92 \mathrm{~mm})$ and $69.3 \pm 11.0 \mathrm{~mm}(50-100 \mathrm{~mm})$ in the DETP and placebo groups, respectively.

\section{Efficacy}

The onset time of analgesic relief data from pooled VAS scores between baseline and day 7 of treatment were summarized by time point (Table 2). At the third hour of treatment, DETP-treated patients showed a significantly reduced mean VAS score compared with placebo (DETP, $54.1 \mathrm{~mm}$; placebo, $60.3 \mathrm{~mm} ; P=0.008$ ); this significance continued through 7 days post-treatment when the mean VAS score for DETP-treated patients was $9.4 \mathrm{~mm}$ compared with
$18.4 \mathrm{~mm}$ in placebo-treated patients $(P<0.0001)$. The total reduction in mean VAS score over the course of the study was $58 \mathrm{~mm}$ for DETP-treated patients compared with $51 \mathrm{~mm}$ for placebo-treated patients. Percent reduction in post-treatment scores from baseline was also calculated for each treatment group to provide additional clinical relevance. Again, by hour 3, patients in the DETP treatment group had achieved a significantly greater percent reduction in VAS score compared with patients in the placebo treatment group (20\% and $13 \%$ reduction, respectively; $P=0.012$; Figure 2); this significance in reduction was sustained through the end of the study at day 7 (86\% and $73 \%$ reduction, respectively; $P<0.0001$; Figure 2). There were a significantly higher number of successes in the DETP treatment group (91\%) compared with the placebo group $(71 \% ; P<0.0001)$ at day 7 .

Pain at rest, pain on passive stretch, and pain on palpation were significantly improved at day 3 and day 7 for DETP-treated compared with placebo-treated patients (Table 3). By day 7, possibility of single foot leaning also 
Table I Patient demographics and other baseline characteristics

\begin{tabular}{|c|c|c|c|}
\hline Parameter ${ }^{\mathrm{a}, \mathrm{b}}$ & $\begin{array}{l}\text { DETP } \\
n=138\end{array}$ & $\begin{array}{l}\text { Placebo } \\
n=136\end{array}$ & $P$ value \\
\hline Age (years) & $\begin{array}{l}34.5 \pm 13.6 \\
(18-65)\end{array}$ & $\begin{array}{l}33.3 \pm 12.3 \\
(18-62)\end{array}$ & 0.42 \\
\hline Height (cm) & $\begin{array}{l}17 \mid .5 \pm 8.9 \\
(150-197)\end{array}$ & $\begin{array}{l}170.0 \pm 8.7 \\
(143-188)\end{array}$ & 0.14 \\
\hline Weight (kg) & $\begin{array}{l}70.1 \pm 12.8 \\
(45-105)\end{array}$ & $\begin{array}{l}67.4 \pm 15.7 \\
(38-168)\end{array}$ & 0.13 \\
\hline $\begin{array}{l}\text { Body mass index } \\
\left(\mathrm{kg} / \mathrm{m}^{2}\right)\end{array}$ & $\begin{array}{l}23.8 \pm 3.9 \\
(16.9-39.4)\end{array}$ & $\begin{array}{l}23.2 \pm 4.2 \\
(16.5-52.4)\end{array}$ & 0.23 \\
\hline \multicolumn{4}{|l|}{ Sex } \\
\hline $\begin{array}{l}\text { Male } \\
\text { Female }\end{array}$ & $\begin{array}{l}79(57 \%) \\
59(43 \%)\end{array}$ & $\begin{array}{l}70(51 \%) \\
66(49 \%)\end{array}$ & 0.34 \\
\hline \multicolumn{4}{|l|}{ Injury characteristics } \\
\hline Time to injury (hours) & $\begin{array}{l}17.7 \pm 11.4 \\
(I-48)\end{array}$ & $\begin{array}{l}19.3 \pm 11.7 \\
(0.5-48)\end{array}$ & 0.28 \\
\hline \multicolumn{4}{|l|}{ Injury location } \\
\hline $\begin{array}{l}\text { Right ankle } \\
\text { Left ankle }\end{array}$ & $\begin{array}{l}84(61 \%) \\
54(39 \%)\end{array}$ & $\begin{array}{l}73(54 \%) \\
62(46 \%)\end{array}$ & 0.26 \\
\hline Swelling $(\mathrm{mm})^{c}$ & $\begin{array}{l}14.5 \pm 10.6 \\
(-10-50)\end{array}$ & $\begin{array}{l}16.9 \pm 11.0 \\
(0-60)\end{array}$ & 0.09 \\
\hline \multicolumn{4}{|l|}{$\begin{array}{l}\text { Functional } \\
\text { impairment, n (\%) }\end{array}$} \\
\hline None & $2(1 \%)$ & $3(2 \%)$ & 0.06 \\
\hline Mild & $39(29 \%)$ & $26(19 \%)$ & \\
\hline Moderate & 62 (45\%) & 60 (44\%) & \\
\hline Severe & $34(25 \%)$ & 47 (34\%) & \\
\hline \multicolumn{4}{|l|}{$\begin{array}{l}\text { Leaning on single } \\
\text { injured foot, } \mathrm{n}(\%)\end{array}$} \\
\hline Possible without pain & $9(7 \%)$ & $10(7 \%)$ & 0.79 \\
\hline Possible with pain & 102 (74\%) & 96 (7I\%) & \\
\hline Not possible & 27 (19\%) & $30(22 \%)$ & \\
\hline \multicolumn{4}{|l|}{ Skin examination } \\
\hline Normal & 134 (97\%) & I 33 (98\%) & 0.72 \\
\hline $\begin{array}{l}\text { Abnormal } \\
\text { (erythema/abrasion) }\end{array}$ & $4(3 \%)$ & $3(2 \%)$ & \\
\hline $\begin{array}{l}\text { Mean pain score } \\
\text { (VAS) }(\mathrm{mm})\end{array}$ & $\begin{array}{l}67.0 \pm 10.6 \\
(50-92)\end{array}$ & $\begin{array}{l}69.3 \pm 11.0 \\
(50-100)\end{array}$ & 0.08 \\
\hline
\end{tabular}

Notes: aData were pooled from Study I and Study 2; ${ }^{\text {bMean }} \pm$ standard deviation (ranges) for continuous variables; number of patients with percentage of total in parenthesis for categorical variables. $P$ values derived from analysis of variance or the Chi-square test. 'Difference in $\mathrm{mm}$ between the submalleolar perimeter of the injured and healthy ankle. Abbreviations: DETP, diclofenac epolamine topical patch; VAS, visual analog scale.

was significantly improved for the DETP treatment group compared with placebo for Study 1 and Study $2(P=0.001$ and $P=0.0003$, respectively; Table 3).

Other secondary efficacy variables included global judgment of efficacy, swelling, and paracetamol consumption. Global efficacy assessments as judged by both the patients and the investigators revealed that the DETP treatment group was superior to the placebo treatment group at day 3 ( $P \leq 0.03$ for all comparisons) and day 7 ( $P \leq 0.001$ for all comparisons; Figure 3$)$. There was no significant difference in swelling between treatment groups for either time point for Study 1, while Study 2 revealed a significant reduction
Table 2 Pooled scores by treatment group for pain on movement: self-assessed by patients on $100 \mathrm{~mm}$ VAS $(0=$ no pain to $100=$ severe pain) from the first day of treatment (day 0 ) through day 7 of the study (day 7)

\begin{tabular}{|c|c|c|c|c|c|c|c|}
\hline Treatment & $\begin{array}{l}\text { Day/time } \\
\text { assessment }\end{array}$ & $\mathbf{N}$ & Mean & Median & SD & Min & Max \\
\hline \multirow[t]{17}{*}{ DETP } & Day $0 / 0 \mathrm{~h}^{\mathrm{a}}$ & 138 & 67.0 & 67.0 & 10.2 & 50.0 & 92.0 \\
\hline & $I h^{b}$ & 138 & 61.7 & 65.5 & 17.6 & 0.0 & 100.0 \\
\hline & $2 h^{b}$ & 138 & 58.5 & 63.0 & 18.6 & 0.0 & 100.0 \\
\hline & $3 \mathrm{~h}^{\mathrm{b}}$ & 138 & 54.1 & 58.0 & 20.0 & 0.0 & 100.0 \\
\hline & $4 h^{b}$ & 138 & 51.7 & 55.0 & 20.0 & 0.0 & 95.0 \\
\hline & $5 \mathrm{~h}^{\mathrm{b}}$ & 138 & 49.3 & 53.5 & 20.0 & 0.0 & 95.0 \\
\hline & $6 \mathrm{~h}^{\mathrm{b}}$ & 138 & 48.1 & 50.0 & 21.0 & 0.0 & 98.0 \\
\hline & $20: 00$ & 138 & 46.8 & 48.5 & 21.3 & 0.0 & 100.0 \\
\hline & Day I/08:00 & 138 & 39.6 & 40.0 & 19.8 & 0.0 & 79.0 \\
\hline & $12: 00$ & 138 & 36.0 & 37.0 & 19.5 & 0.0 & 87.0 \\
\hline & $20: 00$ & 138 & 31.8 & 30.5 & 18.6 & 0.0 & 79.0 \\
\hline & Day 2/08:00 & 138 & 27.8 & 26.0 & 18.1 & 0.0 & 79.0 \\
\hline & $12: 00$ & 138 & 26.0 & 23.5 & 17.5 & 0.0 & 79.0 \\
\hline & $20: 00$ & 138 & 23.8 & 21.0 & 17.6 & 0.0 & 79.0 \\
\hline & Day 3/08:00 & 138 & 20.5 & 20.0 & 16.3 & 0.0 & 79.0 \\
\hline & Day 3 & 138 & 19.0 & 14.5 & 18.1 & 0.0 & 84.0 \\
\hline & Day 7 & 138 & 9.4 & 4.0 & 14.4 & 0.0 & 79.0 \\
\hline \multirow[t]{17}{*}{ Placebo } & Day 0/0 ha & 136 & 69.3 & 69.0 & 11.0 & 50.0 & 100.0 \\
\hline & $\mathrm{Ih}^{\mathrm{b}}$ & 136 & 64.6 & 69.0 & 16.0 & 4.0 & 97.0 \\
\hline & $2 h^{\mathrm{b}}$ & 136 & 62.4 & 65.0 & 16.3 & 2.0 & 98.0 \\
\hline & $3 \mathrm{~h}^{\mathrm{b}}$ & 136 & 60.3 & 64.0 & 16.8 & 2.0 & 90.0 \\
\hline & $4 h^{b}$ & 136 & 58.4 & 60.5 & 17.8 & 3.0 & 94.0 \\
\hline & $5 h^{b}$ & 136 & 56.8 & 59.0 & 17.5 & 2.0 & 94.0 \\
\hline & $6 \mathrm{~h}^{\mathrm{b}}$ & 136 & 55.2 & 57.0 & 17.9 & 2.0 & 95.0 \\
\hline & $20: 00$ & 136 & 54.9 & 55.0 & 18.6 & 0.0 & 90.0 \\
\hline & Day I/08:00 & 136 & 47.4 & 49.5 & 19.8 & 0.0 & 90.0 \\
\hline & $12: 00$ & 136 & 44.5 & 44.5 & 17.3 & 0.0 & 85.0 \\
\hline & $20: 00$ & 136 & 43.6 & 42.0 & 19.9 & 0.0 & 84.0 \\
\hline & Day 2/08:00 & 136 & 37.4 & 36.5 & 19.2 & 0.0 & 89.0 \\
\hline & $12: 00$ & 136 & 34.8 & 33.5 & 18.5 & 0.0 & 79.0 \\
\hline & $20: 00$ & 136 & 34.1 & 32.0 & 20.2 & 0.0 & 90.0 \\
\hline & Day 3/08:00 & 136 & 30.6 & 27.5 & 20.2 & 0.0 & 100.0 \\
\hline & Day 3 & 136 & 29.4 & 29.0 & 20.2 & 0.0 & 75.0 \\
\hline & Day 7 & 136 & 18.4 & 15.0 & 18.2 & 0.0 & 80.0 \\
\hline
\end{tabular}

Notes: ${ }^{a}$ Baseline pretreatment evaluation; 'bours after the first plaster application. Abbreviations: DETP, diclofenac epolamine topical patch; VAS, visual analog scale.

in swelling for the DETP treatment group compared with placebo at both day 3 and day $7(P=0.003$ and $P=0.02$, respectively). At day 7, paracetamol consumption did not differ significantly between treatment groups for either study (Study 1, $P=0.5$; Study 2, $P=0.1$ ).

\section{Safety}

Overall tolerability was judged at day 3 and day 7 by both the patients and the investigators. For both studies the majority of patients and investigators judged tolerability as excellent on a 4-point scale. There was no significant difference between DETP- or placebo-treated patients for either study at day 3 or day 7 in tolerability (Figure 4). In addition, investigators 


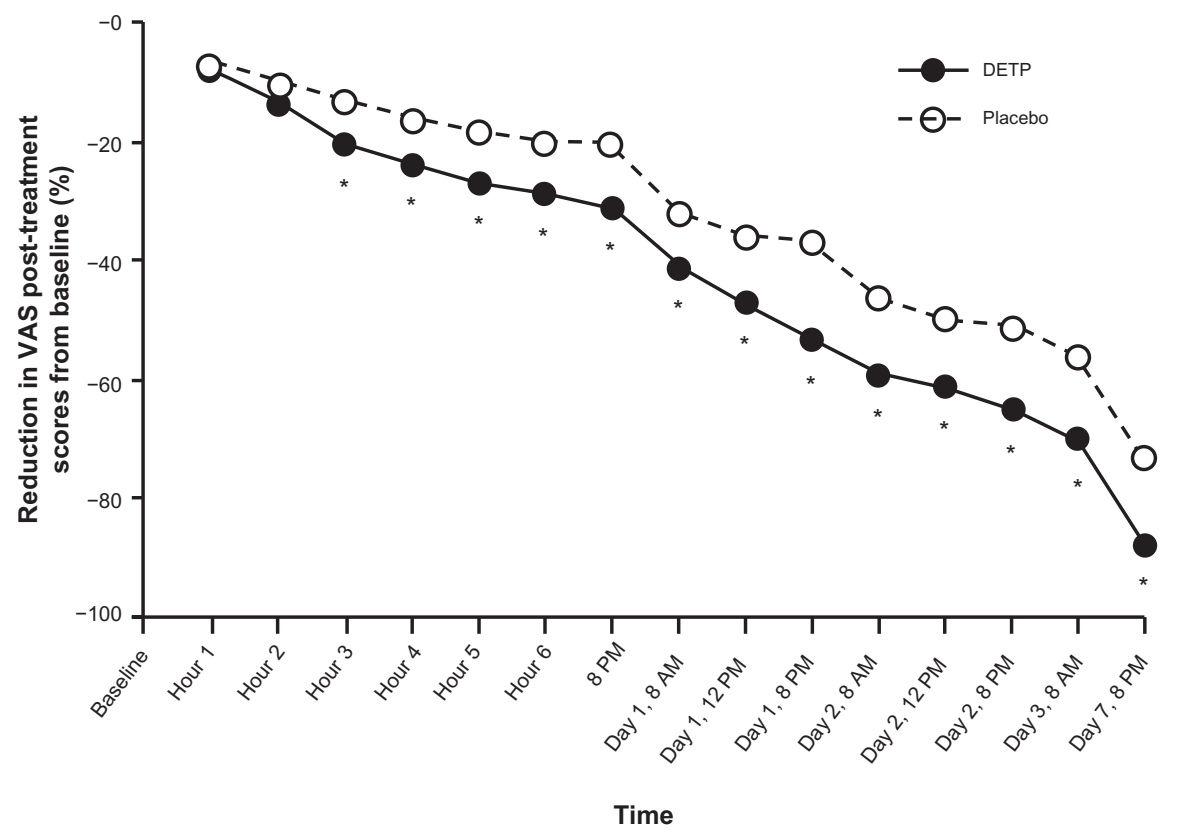

Figure 2 Percent (\%) reduction of post-treatment scores for pain on movement (visual analog scale; VAS) in patients treated with diclofenac epolamine topical patch (DETP) and placebo. Pain reduction was statistically significantly different between treatment groups, favoring DETP treatment, starting 3 hours after initial patch application and continuing through the end of the study (day 7$)$. The asterisk denotes statistical significance $(P \leq 0.05)$.

Table 3 Secondary analgesic efficacy results: individual data from Study I and Study 2

\begin{tabular}{|c|c|c|c|c|c|c|}
\hline \multirow[t]{3}{*}{ Assessment $^{a}$} & \multicolumn{3}{|l|}{ Study I } & \multicolumn{3}{|l|}{ Study 2} \\
\hline & DETP & Placebo & $P$ value $^{b}$ & DETP & Placebo & $P$ value \\
\hline & $n=68$ & $n=66$ & & $n=70$ & $n=66$ & \\
\hline \multicolumn{7}{|l|}{ Pain at rest } \\
\hline \multicolumn{7}{|l|}{ Day 0} \\
\hline None/low/moderate/high & $10 / 32 / 24 / 2$ & $1 \mathrm{I} / 28 / 23 / 4$ & 0.8 & $5 / 26 / 30 / 9$ & $4 / 28 / 30 / 8$ & 0.9 \\
\hline \multicolumn{7}{|l|}{ Day $3^{d}$} \\
\hline None/low/moderate/high & $49 / 18 / 1 / 0$ & $33 / 25 / 8 / 0$ & 0.002 & $51 / 16 / 3 / 0$ & $33 / 29 / 8 / 0$ & 0.007 \\
\hline \multicolumn{7}{|l|}{ Day $7^{d}$} \\
\hline None/low/moderate/high & $60 / 8 / 0 / 0$ & $41 / 19 / 6 / 0$ & 0.001 & $64 / 5 / 0 / 1$ & $46 / 18 / 5 / 1$ & 0.0003 \\
\hline \multicolumn{7}{|l|}{ Pain on passive stretch } \\
\hline \multicolumn{7}{|l|}{ Day 0} \\
\hline None/low/moderate/high & $0 / 4 / 36 / 28$ & $0 / 4 / 29 / 33$ & 0.4 & $0 / 6 / 29 / 35$ & $0 / 4 / 28 / 38$ & 0.8 \\
\hline \multicolumn{7}{|l|}{ Day $3^{d}$} \\
\hline None/low/moderate/high & $12 / 34 / 20 / 2$ & $4 / 26 / 30 / 6$ & 0.003 & $10 / 42 / 17 / 1$ & $5 / 27 / 35 / 3$ & 0.005 \\
\hline \multicolumn{7}{|l|}{ Day $7^{d}$} \\
\hline None/low/moderate/high & $30 / 29 / 7 / 2$ & $17 / 22 / 23 / 4$ & 0.001 & $42 / 22 / 6 / 0$ & $27 / 25 / 15 / 3$ & 0.01 \\
\hline \multicolumn{7}{|l|}{ Pain on palpation } \\
\hline \multicolumn{7}{|l|}{ Day 0} \\
\hline None/low/moderate/high & $0 / 0 / 23 / 45$ & $0 / 2 / 21 / 43$ & 0.7 & $0 / 4 / 23 / 43$ & $0 / 3 / 21 / 46$ & 0.8 \\
\hline \multicolumn{7}{|l|}{ Day $3^{d}$} \\
\hline None/low/moderate/high & $7 / 28 / 25 / 8$ & $2 / 19 / 29 / 16$ & 0.007 & $3 / 46 / 19 / 1$ & $3 / 29 / 30 / 8$ & 0.006 \\
\hline \multicolumn{7}{|l|}{ Day $7^{\mathrm{d}}$} \\
\hline None/low/moderate/high & $20 / 33 / 12 / 3$ & $8 / 25 / 20 / 13$ & 0.001 & $29 / 35 / 6 / 0$ & $16 / 33 / 17 / 3$ & 0.005 \\
\hline \multicolumn{7}{|l|}{ Possibility of single foot leaning } \\
\hline \multicolumn{7}{|l|}{ Day 0} \\
\hline OK without pain/OK with pain/impossible & $4 / 52 / 12$ & $6 / 44 / 16$ & 0.7 & $5 / 50 / 15$ & $4 / 52 / 14$ & 0.9 \\
\hline \multicolumn{7}{|l|}{ Day $3^{d}$} \\
\hline OK without pain/OK with pain/impossible & $36 / 31 / 1$ & $23 / 37 / 6$ & 0.002 & $43 / 27 / 0$ & $35 / 33 / 1$ & 0.3 \\
\hline \multicolumn{7}{|l|}{ Day $7^{\mathrm{d}}$} \\
\hline OK without pain/OK with pain/impossible & $56 / 11 / 1$ & $37 / 28 / 1$ & 0.001 & $63 / 7 / 0$ & $44 / 26 / 0$ & 0.0003 \\
\hline
\end{tabular}

Notes: ${ }^{a} \mathrm{n}$ values are presented for each category; ${ }^{\mathrm{b}} \mathrm{Chi}$-square Mantel Haenszel test for trend; 'Fisher exact test; ${ }^{d}$ or last known value.

Abbreviation: DETP, diclofenac epolamine topical patch. 


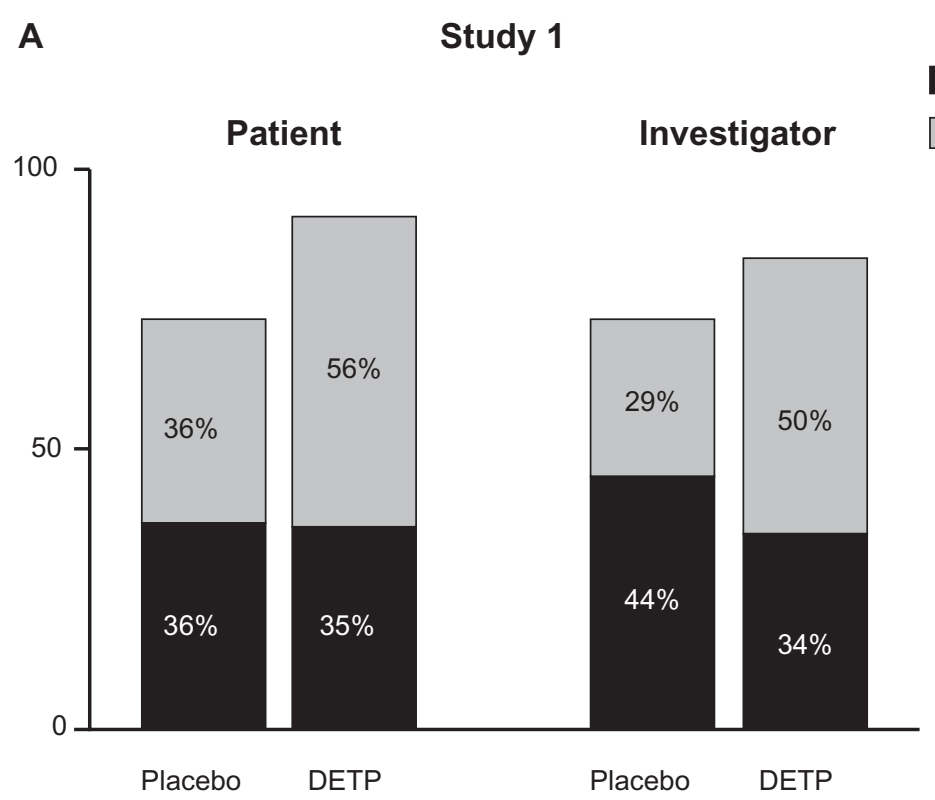

B

Study 2

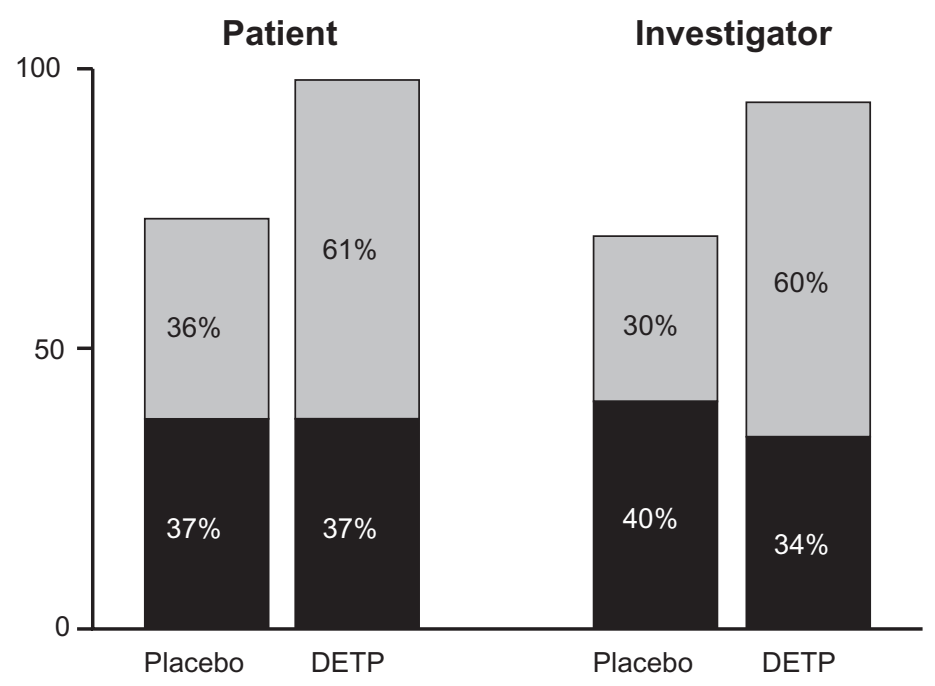

Figure 3 Global efficacy assessments for each treatment group judged by both patients and investigators at day 7 for Study I A) and Study 2 B). This assessment revealed that, for both studies, the diclofenac epolamine topical patch (DETP) treatment was superior to placebo treatment at day 7; day 3 analyses demonstrated comparable results (not shown).

recorded any AEs that occurred during the study. In total, 5 patients ( 2 receiving DETP, 3 receiving placebo) reported AEs in Study 1 (Table 4). These events were primarily application-site reactions and were of mild to moderate severity (Table 4). Only $1 \mathrm{AE}$ (pruritus of mild severity) led to the patient withdrawing from the study. No AEs were reported during Study 2.

\section{Discussion}

This pooled post hoc analysis further demonstrated the efficacy of DETP compared with placebo for controlling pain associated with acute mild-to-moderate ankle sprain in patients for whom NSAID therapy was indicated. DETP produced a statistically significant reduction of pain on movement versus placebo patch by as early as 3 hours following the first patch application. Furthermore, statistically significant pain relief was maintained in the DETP treatment group throughout the 7-day study duration.

Secondary analgesic efficacy measures also favored DETP over placebo patch at most time points. These included pain at rest, pain on passive stretch, pain on palpation, and 
A

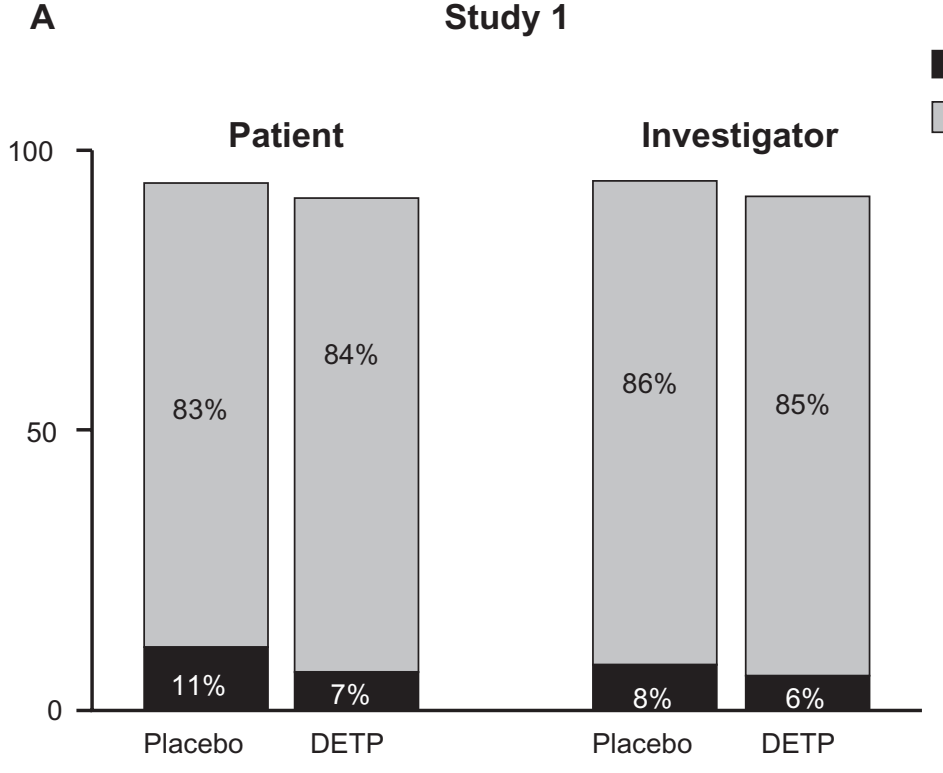

B

Study 2

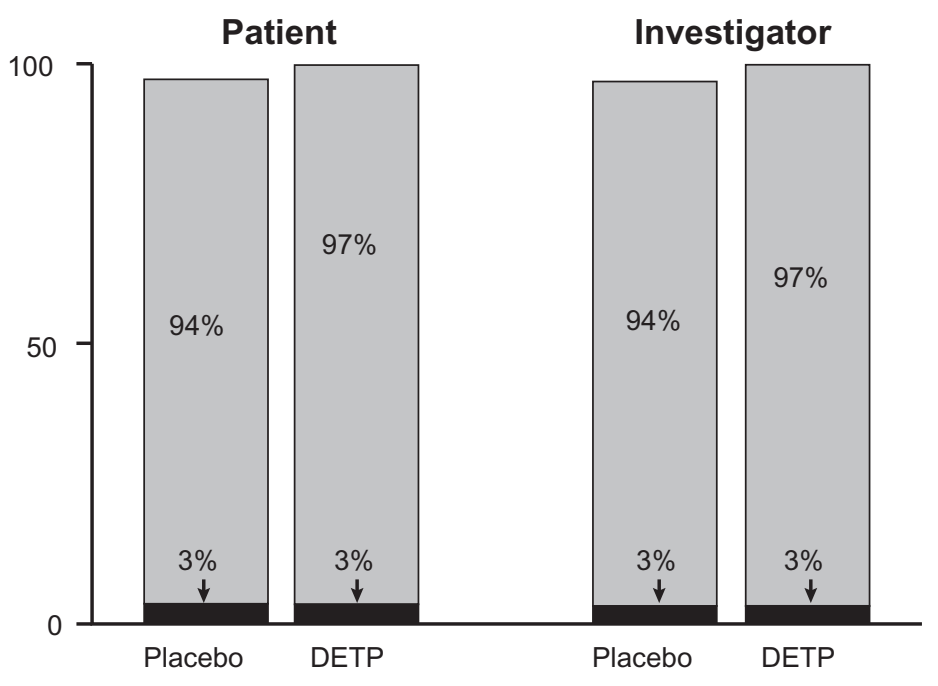

Figure 4 Overall tolerability of diclofenac epolamine topical patch (DETP) or placebo for each treatment group, assessed by patients and investigators at day 7 for Study I A) and Study 2 B). The majority of patients in both treatment groups judged the patch tolerability as excellent. No significant differences were found between DETP- and placebo-treated patients at day 7; results from day 3 tolerability assessments were comparable (not shown).

possibility of single foot leaning. Importantly, a statistically significant benefit was attained between treatment groups for single foot leaning at day 3 in Study 1 and day 7 in both studies. Furthermore, global efficacy assessments completed by the patients and the investigators, as well as treatment success levels determined at the end of the study, favored the DETP.

The results for DETP efficacy compare favorably to other topical NSAID trials. Combined analysis of 37 placebo controlled acute pain trials for topical NSAIDs (other than diclofenac) showed efficacy for placebo of 39\% compared with $71 \%$ for patients receiving active treatment. ${ }^{28}$ Despite this relatively high placebo effect, the active topical treatments were nevertheless considered to be significantly more effective than placebo in the treatment of acute pain.

Clearly, NSAIDs are an effective remedy for acute pain. However, they carry significant risk of potential side effects associated with their use, especially in patients already at elevated risk for GI or cardiovascular events due to pre-existing conditions. Our pooled study population was 
Table 4 Summary of adverse events reported during Study I

\begin{tabular}{|c|c|c|}
\hline & DETP & Placebo \\
\hline Number of patients & $68^{\mathrm{a}}$ & $66^{\mathrm{a}}$ \\
\hline Patients reporting events, n (\%) & $2(3 \%)$ & $3(5 \%)$ \\
\hline Number of adverse events reported & 2 & 3 \\
\hline \multicolumn{3}{|l|}{ Number of events by severity } \\
\hline Mild & 0 & 2 \\
\hline Moderate & 2 & 1 \\
\hline Severe & 0 & 0 \\
\hline Not reported & 0 & 0 \\
\hline \multicolumn{3}{|l|}{ Events by body system, n (\%) } \\
\hline Skin & I (I\%) & $3(5 \%)$ \\
\hline Pruritus & I (I\%) & $2(3 \%)$ \\
\hline Other (application site burning) & $0(0 \%)$ & I (2\%) \\
\hline Body as a whole & $\mathrm{I}(\mathrm{l} \%)$ & $0(0 \%)$ \\
\hline Allergic reaction & I (l\%) & $0(0 \%)$ \\
\hline
\end{tabular}

Note: ${ }^{a}$ Only results from Study I are presented; there were no adverse events reported during Study 2.

Abbreviation: DETP, diclofenac epolamine topical patch.

limited in number and diversity of baseline risk factors. These limitations preclude any reliable estimate of GI or cardiovascular risk from DETP based on these results across the general population. A total of 5 AEs in the 274 patients enrolled were reported; all AEs were related to application-site reactions or allergic reactions, and 3 of these events were reported in placebo treated patients. No reported AEs were related to the GI system. The incidence of AEs reported in this combined analysis is far below that reported in studies of oral NSAIDs, including oral diclofenac. In one 14-day study of 60 patients with acute shoulder pain receiving $75 \mathrm{mg}$ oral diclofenac twice daily, 23 patients experienced AEs, 16 of which were GI related..$^{29}$ This is consistent with results from a long-term study evaluating AEs in more than 2000 patients with rheumatoid arthritis receiving $75 \mathrm{mg}$ oral diclofenac twice a day for up to 33 months. In this study, $6.9 \%$ of patients receiving diclofenac discontinued due to GI AEs within the first 12 months of the study. ${ }^{30}$

\section{Conclusion}

This pooled analysis of 2 independently conducted studies validated their conclusions that, for patients with mildto-moderate ankle sprain requiring adjunctive NSAID therapy, treatment with DETP for 7 days provides significantly effective and durable relief of acute pain within 3 hours of the first patch application. The DETP was also generally well tolerated. As a topical therapy, DETP can provide a safe and effective treatment alternative, which might provide less systemic exposure to NSAIDs than oral medications.
We acknowledge that there are certain limitations and shortfalls associated with this pooled data set. A metaanalysis usually requires many trials, in part to allow for the multiplicity of effects due to variations in methods, materials, sites, and measured outcomes; each and all of which may confound the determination of drug effect. Our approach was to combine data from 2 very similar studies to determine if the independently obtained conclusions held across the expanded population. While our analysis is retrospective in scope, the studies reviewed represent prospective level-one evidence, which self adjudicates by the strict adherence to identical enrollment and end point determinations. Where variance occurred in efficacy metrics, validated statistical comparisons minimize these differences, while the high number of subjects $(\mathrm{N}=274)$ minimizes oversights in type I or II errors.

\section{Acknowledgments}

These studies were sponsored by Laboratoires Genévrier and Institut Biochimique SA (IBSA). The sponsors wish to thank the principal investigators and site staff who participated in the studies analyzed in this publication: Dr Eric Joussellin's staff at the Institut National du Sport (INSEP) in Paris, France, and Professor Gerard Saillant's staff at the Othopedic and Traumatology Surgery Unit, Hôpital de la Pitié in Paris, France. We thank Drs Paul Cavanaugh and Craig Paterson (King Pharmaceuticals ${ }^{\circledR}$, Inc which was acquired by Pfizer Inc in March 2011) and Guiliana Villa (IBSA) for critical review of the manuscript. We also acknowledge the writing and editorial assistance provided by MMS Holdings Inc (Canton, MI, USA) and Quintiles Medical Communications (Parsippany, NJ, USA). Funding was provided by King Pharmaceuticals $^{\circledR}$, Inc (which was acquired by Pfizer Inc in March 2011), for assistance with the preparation of this manuscript.

\section{Disclosure}

Author David R Lionberger is a consultant for Pfizer Inc., Aesculap-B Braun Melsungen AG, Smith and Nephew, and King Pharmaceuticals ${ }^{\circledR}$, Inc. Authors Jillmarie Yanchick and Merrell Magelli were employees of Alpharma Pharmaceuticals, LLC, a wholly owned subsidiary of King Pharmaceuticals ${ }^{\circledR}$, Inc (acquired by Pfizer Inc in March 2011), which markets diclofenac epolamine topical patch $1.3 \%$ (DETP), at the time of this work. Author Arturo Lanzarotti is an employee of Institut Biochimique SA (IBSA) which sponsored the DETP studies described herein. 


\section{References}

1. Fong DT, Hong Y, Chan LK, Yung PS, Chan KM. A systematic review on ankle injury and ankle sprain in sports. Sports Med. 2007;37(1): 73-94.

2. Simon TD, Bublitz C, Hambidge SJ. Emergency department visits among pediatric patients for sports-related injury: basic epidemiology and impact of race/ethnicity and insurance status. Pediatr Emerg Care. 2006;22(5):309-315.

3. Soboroff SH, Pappius EM, Komaroff AL. Benefits, risks, and costs of alternative approaches to the evaluation and treatment of severe ankle sprain. Clin Orthop Relat Res. 1984;(183):160-168.

4. Wolfe MW, Uhl TL, Mattacola CG, McCluskey LC. Management of ankle sprains. Am Fam Physician. 2001;63(1):93-104.

5. Moran M. Double-blind comparison of diclofenac potassium, ibuprofen and placebo in the treatment of ankle sprains. J Int Med Res. 1991;19(2): 121-130.

6. Diaz JA, Cuervo C, Valderrama AM, Kohlel J. Valdecoxib provides effective pain relief following acute ankle sprain. J Int Med Res. 2006; 34(5):456-467.

7. Lanas A. Cyclo-oxygenase-1/cyclo-oxygenase-2 non selective nonsteroidal anti-inflammatory drugs: epidemiology of gastrointestinal events. Dig Liver Dis. 2001;33(Supp1 2):S29-S34.

8. Moore RA, Derry S, McQuay HJ. Cyclo-oxygenase-2 selective inhibitors and nonsteroidal anti-inflammatory drugs: balancing gastrointestinal and cardiovascular risk. BMC Musculoskelet Disord. 2007; 8:73.

9. Fries JF, Williams CA, Bloch DA, Michel BA. Nonsteroidal antiinflammatory drug-associated gastropathy: incidence and risk factor models. Am J Med. 1991;91(3):213-222.

10. Wolfe MM, Lichtenstein DR, Singh G. Gastrointestinal toxicity of nonsteroidal antiinflammatory drugs. $N$ Engl J Med. 1999;340(24): 1888-1899.

11. Kearney PM, Baigent C, Godwin J, et al. Do selective cyclo-oxygenase2 inhibitors and traditional non-steroidal anti-inflammatory drugs increase the risk of atherothrombosis? Meta-analysis of randomised trials. BMJ. 2006;332(7553):1302-1308.

12. Solomon SD, McMurray JJ, Pfeffer MA, et al; for the Adenoma Prevention with Celecoxib (APC) Study Investigators. Cardiovascular risk associated with celecoxib in a clinical trial for colorectal adenoma prevention. N Engl J Med. 2005;352(11):1071-1080.

13. Sopena F, Lanas A. How to advise aspirin use in patients who need NSAIDs. Curr Pharm Dis. 2007;13(22):2248-2260.

14. Capone ML, Sciulli MG, Tacconelli S, et al. Pharmacodynamic interaction of naproxen with low-dose aspirin in healthy subjects. J Am Coll Cardiol. 2005;45(8):1295-1301.

15. Catella-Lawson F, Reilly MP, Kapoor SC, et al. Cyclooxygenase inhibitors and the antiplatelet effects of aspirin. $N$ Engl J Med. 2001; 345(25):1809-1817.

16. Ouellet M, Riendeau D, Percival MD. A high level of cyclooxygenase2 inhibitor selectivity is associated with a reduced interference of platelet cyclooxygenase-1 inactivation by aspirin. Proc Natl Acad Sci U S A. 2001;98(25):14583-14588.

17. Food and Drug Adminstration. Information for Healthcare Professionals: Concomitant Use of Ibuprofen and Aspirin. 2006. http://www.fda.gov/ Drugs/DrugSafety/Postmarket Drug Safety Information for Patients and Providers/ucm125222.htm. Accessed January 13, 2011.
18. Renda G, Tacconelli S, Capone ML, et al. Celecoxib, ibuprofen, and the antiplatelet effect of aspirin in patients with osteoarthritis and ischemic heart disease. Clin Pharmacol Ther. 2006;80(3):264-274.

19. Petersen B, Rovati S. Diclofenac epolamine (Flector) patch: evidence for topical activity. Clin Drug Investig. 2009;29(1):1-9.

20. Joussellin E. Flector Tissugel ${ }^{\circledR}$ dans le traitement des entorses douloureuses de la cheville [Flector Tissugel ${ }^{\circledR}$ in the treatment of painful ankle sprain]. J Traumatol Sport. 2003;20:1S5-1S9.

21. Rowbotham MC, Galer BS, Block JA, et al. Flector Tissugel ${ }^{\circledR}$ : efficacité et tolérance dans le traitement des microtraumatismes sportifs. Données d'une étude contrôlée conduite aux Etats-Unis [Flector Tissugel ${ }^{\circledR}$ : efficacy and safety in the treatment of minor sports injuries. Data from a controlled trial in the United States]. J Traumatol Sport. 2003; 20:1S15-11S20.

22. Saillant G. Étude comparant l'efficacité et la tolérance de Flector Tissuge ${ }^{\circledR}$ à celles d'un placebo dans le traitement des entorses bénignes de la cheville. [Study comparing the efficacy and tolerance of Flector Tissugel ${ }^{\circledR}$ to that of a placebo in the treatment of benign ankle sprains]. Medicine du Sport. 1998;72:1-5.

23. Brühlmann P, de Vathaire F, Dreiser RL, Michel BA. Short-term treatment with topical diclofenac epolamine plaster in patients with symptomatic knee osteoarthritis: pooled analysis of two randomised clinical studies. Curr Med Res Opin. 2006;22(12):2429-2438.

24. Arroyo JF, Vathaire F, Mautone G. A study of the short-term efficacy of Flector EP Tissugel (Diclofenac epolamine) for the local treatment of abarticular pathologies of the shoulder and the knee in elderly subjects. [Clinical Study Report]. Data on file. King Pharmaceuticals ${ }^{\circledR}$, Inc.; 2002.

25. Jenoure P, Segesser B, Luhti U, Gremion G. A trial with diclofenac HEP plaster as topical treatment in minor sport injuries. Drugs Exp Clin Res. 1993;19(3):125-131.

26. Rainsford KD, Kean WF, Ehrlich GE. Review of the pharmaceutical properties and clinical effects of the topical NSAID formulation, diclofenac epolamine. Curr Med Res Opin. 2008;24(10):2967-2992.

27. Giamberadiono M. Effects of topical diclofenac on pain and periarticular pain sensitivity in patients with osteoarthritis of the knee. Flector Tissugel $^{\circledR}$ : Diclofenac Epolamine Plaster Product Monograph. Pambio-Noranco, Switserland: Institut Biochimique SA July, 2005. Clinical Efficacy of Flector EP Tissuegel. 2005:49-51.

28. Moore RA, Tramer MR, Carroll D, Wiffen PJ, McQuay HJ. Quantitative systematic review of topically applied non-steroidal anti-inflammatory drugs. BMJ. 1998;316(7128):333-338.

29. Wober W. Comparative efficacy and safety of nimesulide and diclofenac in patients with acute shoulder, and a meta-analysis of controlled studies with nimesulide. Rheumatology (Oxford). 1999;38(Suppl 1):33-38.

30. Krueger K, Lino L, Dore R, et al. Gastrointestinal tolerability of etoricoxib in rheumatoid arthritis patients: results of the etoricoxib vs diclofenac sodium gastrointestinal tolerability and effectiveness trial (EDGE-II). Ann Rheum Dis. 2008;67(3):315-322.
Open Access Journal of Sports Medicine

\section{Publish your work in this journal}

Open Access Journal of Sports Medicine is an international, peer-reviewed, open access journal publishing original research, reports, reviews and commentaries on all areas of sports medicine. The manuscript management system is completely online and includes a very quick and fair peer-review system.

\section{Dovepress}

Visit http://www.dovepress.com/testimonials.php to read real quotes from published authors. 